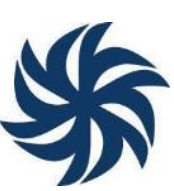

\title{
JORNALISMO E INVISIBILIDADE DO CONFLITO AMBIENTAL NO CASO DA CMPC CELULOSE RIOGRANDENSE
}

\section{JOURNALISM AND INVISIBILITY OF ENVIRONMENTAL CONFLICT IN THE CASE OF CMPC CELULOSE RIOGRANDENSE}

\section{PERIODISMO Y INVISIBILIDAD DEL CONFLICTO AMBIENTAL EN EL CASO DE LA CMPC CELULOSE RIOGRANDENSE}

\author{
Cláudia Herte de Moraes* \\ Eliege Maria Fante**
}

\begin{abstract}
Resumo: $\mathrm{O}$ artigo apresenta uma reflexão sobre a (in) visibilidade do conflito ambiental decorrente da quadruplicação da unidade da empresa CMPC Celulose Riograndense, em Guaíba/RS. A busca nos sites dos dois maiores jornais do Rio Grande do Sul indicou a publicação de apenas uma notícia sobre a pauta pelo Correio do Povo e nenhuma pelo Zero Hora, não obstante tenhamos identificado valores-notícia segundo Silva (2014). O período da análise contemplou o segundo ano após a quadruplicação (maio de 2016 a maio de 2017) quando a poluição (forte mau odor e barulho alto e ininterrupto, principalmente) emitida pela mesma ultrapassou os limites legais. A partir da Análise de Conteúdo temática das notícias jornalísticas repercutidas na rede social Facebook, pelo grupo de vizinhos da CMPC Celulose Riograndense: "Não Somos Todos CMPC: Somos Todos Guaíba", constatamos que a cobertura do conflito ambiental e do sofrimento da vizinhança aconteceu principalmente em meios ligados a entidades ambientais.
\end{abstract}

Palavra-chave: Jornalismo; Conflito ambiental; Celulose e papel; Facebook; Análise de Conteúdo.

\begin{abstract}
The article presents a reflection on the (in) visibility of the environmental conflict resulting from the quadruplication of the CMPC Celulose Riograndense unit in Guaíba/RS. The search on the sites of the two largest newspapers in Rio Grande do Sul indicated the publication of only one news about the agenda by the Correio do Povo and none by Zero Hora, although we identified news values according to Silva (2014). The period of analysis included the second year after the quadruplication (May 2016 to May 2017) when the pollution (strong bad odor and loud and uninterrupted noise, mainly) emitted by it exceeded the legal limits. From the thematic Content Analysis of the news stories reverberated in the social network Facebook, by the group of neighbors of CMPC Celulose Riograndense: "We are not all CMPC: We are all
\end{abstract}

\footnotetext{
*Jornalista doutora em Comunicação e Informação, professora no Departamento de Ciências da Comunicaçação. Líder do Grupo de Pesquisa Midiação - Educomunicação e Meio Ambiente. Universidade Federal de Santa Maria (UFSM). E-mail: chmoraes@ gmail.com. ORCID iD: https://orcid.org/0000-0003-3233-311X

** Jornalista. Mestre e doutoranda em Comunicação e Informação da Universidade Federal do Rio Grande do Sul (UFRGS). E-mail: gippcom@gmail.com
} 
Guaiba", we found that the coverage of the environmental conflict and the suffering of the neighborhood happened mainly in media linked to environmental entities.

Keywords: Journalism; Environmental conflicto; Pulp and paper; Facebook; Content analysis.

Resumen: El artículo presenta una reflexión sobre la (in) visibilidad del conflicto ambiental resultante de la cuadruplicación de la unidad CMPC Celulose Riograndense en Guaíba/RS. La búsqueda en los sitios de los dos periódicos más grandes de Rio Grande do Sul indicó la publicación de una sola noticia sobre la agenda por parte del Correio do Povo y ninguna por Zero Hora, aunque identificamos los valores de las noticias según Silva (2014). El período de análisis incluyó el segundo año después de la cuadruplicación (mayo de 2016 a mayo de 2017) cuando la contaminación (fuerte mal olor y ruido fuerte e ininterrumpido, principalmente) emitida por él excedió los límites legales. Desde el Análisis de Contenido temática de las noticias reflejadas en la red social Facebook, por el grupo de vecinos CMPC Celulose Riograndense: "No todos somos CMPC: somos todos Guaíba", descubrimos que la cobertura del conflicto ambiental y del sufrimiento del vecindario ocurrieron principalmente en medios vinculados a entidades ambientales.

Palabras clave: Periodismo; Conflictos ambientales; Pulpa y papel; Facebook; Análisis de contenido.

\section{Introdução}

Não é exagero dizer que todo o jornalismo gaúcho cobriu a inauguração da quadruplicação da CMPC Celulose Riograndense em Guaíba (RS), em maio de 2015. Em seu site o Zero Hora (CALDAS, 2017) explicou dois dias antes que, por a logística exigir 48 horas de intervalo entre os processos, o primeiro de "[...] cozimento da madeira picada [...]" se iniciaria no domingo (3) às 19h, e "[...] a montagem de fardos de placas de celulose que serão [iam] enviadas ao Exterior", portanto, aconteceria na terça-feira 5 de maio. Contudo, o jornalismo gaúcho de referência não dedicou a mesma cobertura nos dias, meses e anos seguintes ao outro lado dos altos muros da fábrica: o da vizinhança. Esta constatação decorre do resultado do levantamento realizado nos sites dos dois maiores jornais do Estado, Correio do Povo (CP) e Zero Hora (ZH), sendo que o primeiro publicou apenas uma notícia com esta pauta e, o segundo, nenhuma. As informações sobre a situação sofrida pela vizinhança da fábrica foram obtidas com a leitura das postagens feitas na página em rede social de moradores e moradoras do Balneário Alegria intitulada "Não Somos Todos CMPC: Somos Todos Guaíba" (doravante "Não-Somos"). Além da tomada de conhecimento sobre os impactos enfrentados, selecionamos, para a nossa análise, as postagens do segundo ano após a quadruplicação, entre maio de 2016 e maio de 2017, as quais incluem a referida notícia publicada pelo $\mathrm{CP}$, duas notícias do jornal Extra Classe; duas notícias da Associação Gaúcha de Proteção ao Ambiente Natural (Agapan) e uma notícia da Associação Amigos do Meio Ambiente de Guaíba (AMA). 
$\mathrm{Na}$ página Não Somos, encontramos 82 postagens no total, com exposição de reclamações, tanto de forma direta quanto por republicações de outros posts de perfis pessoais e de outras páginas: mau odor, fedor, barulho absurdo, barulheira, decibéis inaceitáveis. Na sequência, vamos aprofundar alguns aspectos sobre os dois posts que obtiveram o maior número de compartilhamentos e os 15 posts que receberam um número maior de comentários em relação aos demais. Reclamações, críticas e pedidos de providências da população afetada (que inclui moradores de diversos bairros de Guaíba e da Zona Sul de Porto Alegre) progridem assim como a fábrica, desde a histórica norueguesa Borregaard que iniciou suas atividades em 17 de março de 1972, passando a denominar-se Riocell por meio do governo militar brasileiro, sob o domínio do Grupo Sul Brasileiro/Montepio da Família Militar desde 1974/1975, à Aracruz com os grupos Klabin, Ioschpe e Votorantim em março de 1982, a qual acabou vendida em setembro de 2009 para a Votorantim Celulose e Papel (VCP), constituindo assim a Fibria, que manteve o nome Aracruz até dezembro do mesmo ano, quando houve a aquisição pela chilena Compañía Manufacturera de Papeles y Cartones (CMPC) que adotou o "nome regionalizado" Celulose Riograndense.

Nosso objetivo é refletir sobre a temática do conflito ambiental em questão, identificando a qualidade da visibilidade trazida pelo jornalismo de referência, bem como por outros meios de comunicação. Em especial, pela página na rede social Facebook Não Somos, que difundiu o impacto causado pelo megaempreendimento. No período da análise, entre maio de 2016 e maio de 2017, a poluição (forte mau odor e barulho alto e ininterrupto, principalmente) emitida pela fábrica ultrapassou todos os limites, tendo sido multada nove vezes pelo órgão ambiental do Estado responsável pelo licenciamento (NENÊ, 2017). Os fatos envolvidos poderiam ter sido pauta do jornalismo de referência visto os valores-notícia presentes (SILVA, 2014). Para substancializar nossa reflexão contamos com as contribuições de Acselrad (2005) sobre conflito ambiental, bem como os autores da área da comunicação, cidadania e ambiente, entre os principais Soares (2008; 2009) e Girardi et al (2012).

\section{Conflitos ambientais e jornalismo}

Os conflitos ambientais são a face mais direta da disputa que há na sociedade, quando tratamos da relação meio ambiente - cidadania. Enquanto para alguns é o direito que falta, para outros sobram privilégios. Importa examinar que forma o jornalismo está - ou não - dando conta dessas disputas, como de fato caberia fazê-lo. Por isso, consideramos importante trazer o conceito de conflito ambiental de Henri Acselrad (2005, p. 26), segundo o qual a partir dos "[...] modos diferenciados de apropriação, uso e significação do território [...]" pelos diversos grupos sociais, acontece quando um ou mais deles se percebe ameaçado e/ou impedido de continuar as suas atividades em decorrência do surgimento de outro modo de apropriação, uso e significação 
praticado por um outro grupo social.

Há quatro dimensões constitutivas nos conflitos ambientais: apropriação material e apropriação simbólica, durabilidade e interatividade espacial das práticas sociais (ACSELRAD, 2005). A primeira consiste na apropriação dos bens naturais, os chamados recursos, como água, pela apropriação de rios, etc. A segunda se evidencia pelo uso de discursos exaltando uma suposta "vocação natural" do local, a "sustentabilidade" de determinado negócio, etc. Sobre estas duas dimensões, Acselrad (2005, p. 24) enfatiza a importância da atenção sobre "os critérios de avaliação e de legitimação" na discussão sobre conflitos, que: “[...] podem se configurar tanto através de uma luta direta no espaço de distribuição de poder sobre a base material, como uma luta simbólica em torno às categorias de legitimação das práticas." Nesta "luta simbólica" o jornalismo tem o papel essencial de distinguir o que são práticas tradicionais, originárias e/ou modos de viver nos distintos períodos históricos dos lugares objetos de disputa pelos projetos de desenvolvimento, do que é propaganda e falácia difundida pelos seus mentores, para não difundir discursos que reproduzam as injustiças.

De volta às dimensões constitutivas, a terceira elaborada por Acselrad (2005, p. 26), a durabilidade, é aquela pela qual se percebe a ameaça ou o impedimento que um grupo social tem para continuar o mesmo modo de apropriação do território bem como a manutenção das suas práticas sociais que dele dependem, devido a ações e/ou intervenções de outro grupo. A quarta dimensão, interatividade, se manifesta por meio dos efeitos "não-mercantis e indesejáveis de uma prática sobre outra prática". $\mathrm{O}$ autor recorda que na linguagem econômica chama-se "externalidade". Com frequência, esta palavra expressa algum malefício causado ao meio ambiente, como poluição da água e do ar, o que atinge a comunidade que depende destes bens naturais e coletivos.

A flexibilização das normas ambientais e a fragilização dos órgãos de meio ambiente, iniciada nos anos 1990, resultou numa despolitização das questões ambientais e, ao mesmo tempo, ocorre a opção do poder pela imposição de um suposto consenso. Este, na prática, consiste mais no sufocamento ou não reconhecimento de que o conflito pode ser fruto de uma simples democracia imagética, do que a "[...] expressão de diferenças reais entre atores e projetos sociais a serem trabalhadas no espaço público". (ACSELRAD, 2005, p. 29). Cabe ao jornalismo confrontar os discursos dos poderes público e privado com os das populações afetadas para discutir o projeto de desenvolvimento, desta forma abarcando o debate sobre as dimensões do conflito ambiental.

2.1 A produção de celulose e suas consequências

Em relação aos conflitos ambientais decorrentes da atividade econômica ligada à celulose no Rio Grande do Sul, estudos acadêmicos (BINKOWSKI, 2009; BARENHO, 2008) abordam dos impactos sobre as populações afetadas nos municípios onde a silvicultura se instalou, ou seja, 
os plantios dos monocultivos arbóreos. Estes impactos vão desde a poluição pelo uso de agrotóxicos, o comprometimento e ameaça à conservação dos ecossistemas naturais e sua biodiversidade, até a desestruturação das comunidades e vilas rurais e de laços comunitários e familiares. Há registros do surgimento e/ou grave aumento de delitos nestes locais como roubo, furto, estupro, violência contra a mulher.

Entretanto pouco se fala quanto aos impactos ambientais e sociais no meio urbano provocados pela fábrica instalada na orla do Lago Guaíba, manancial que abastece a população de cinco municípios (Porto Alegre, Guaíba, Viamão, Eldorado do Sul e Barra do Ribeiro) estimada em 1.891.914 habitantes segundo o IBGE (2019). Menos ainda sobre o sofrimento da vizinhança residente no Balneário Alegria, local histórico de turismo e recreação. Este conflito ambiental é ignorado pelos meios de comunicação em geral. Em documento de 25 de maio de 2017 distribuído à imprensa, a Associação dos Moradores do Balneário Alegria (ABA), demarca o mês de agosto de 2013, com o início do Projeto Guaíba 2 (quadruplicação), para a piora significativa na qualidade de vida da vizinhança:

[...] uma das ruas mais antigas da cidade não estava inclusa para ser incorporada ao pátio da empresa, deixando a zona sul [de Guaíba] com uma única via de acesso. $\mathrm{O}$ empreendimento avançou sua área física em direção aos imóveis vizinhos, de famílias que já eram nativas do balneário, muito antes da chegada da primeira empresa de celulose se instalar no local, hoje os imóveis pertencem aos seus descendentes. (ASSOCIAÇÃO DOS MORADORES DO BALNEÁRIO ALEGRIA, 2017).

Na imagem a seguir (Figura 1) visualizamos em amarelo a área da fábrica e os bairros no entorno indicados pela seta vermelha, cuja vizinhança é a que está mais mobilizada em denunciar o sofrimento e os impactos aos quais estão submetidos: Alegria, Vila Elza e Alvorada. 
Figura 1 - Localização da fábrica CMPC e bairros do entorno

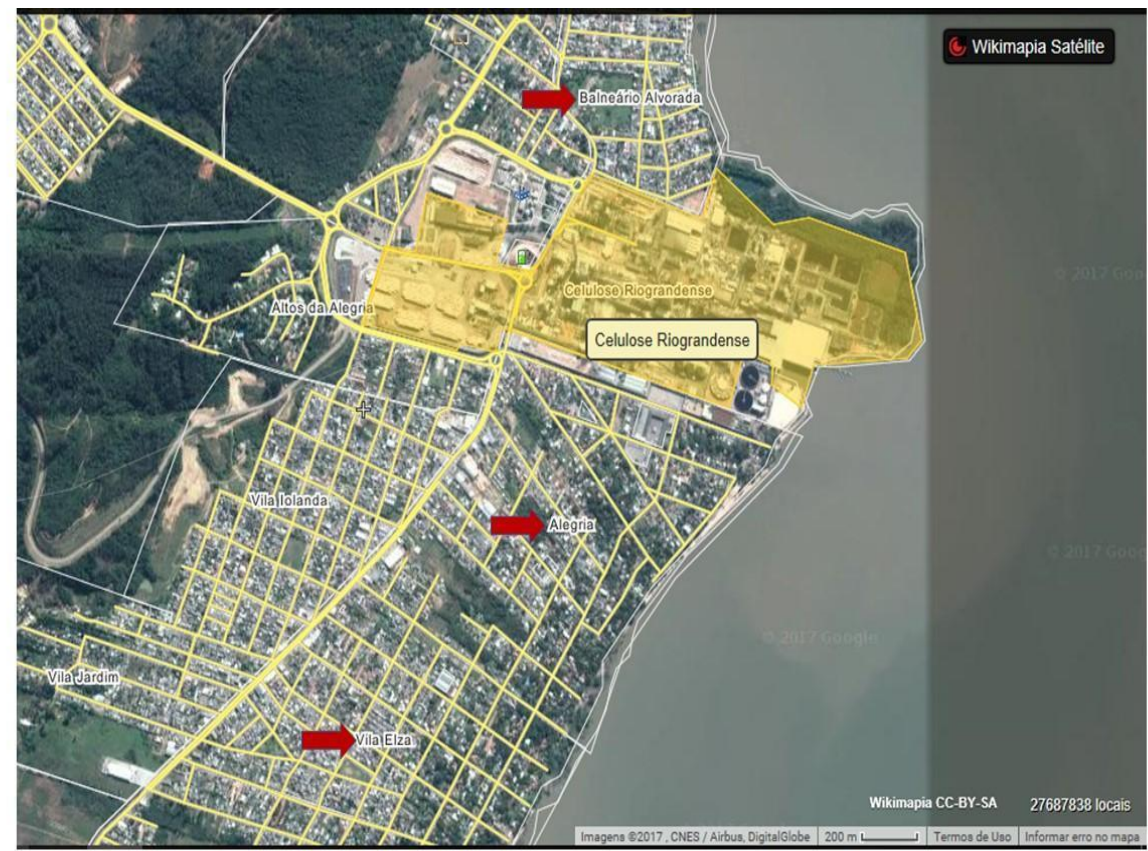

Fonte: Wikimapia, 2017.

A página "Não-Somos" se propõe a "[...] ser um espaço de discussão e de solução dos problemas" relacionados ao funcionamento da fábrica "[...] e que afetam diretamente grande parte dos moradores dos bairros Alegria, Flórida, Vila Elza e imediações”. Afirma que busca “[...] fazer contraponto às defesas incondicionais à CMPC - insensíveis aos problemas causados a[os] moradores próximos - com base em fatos".

Em um dos 15 posts mais comentados no período de nossa análise (30 de julho de 2016), o debate é justamente sobre o direito a continuar vivendo no local, colocado em questão frequentemente pelos próprios moradores do município. Um exemplo da dimensão constitutiva do conflito ambiental "interatividade" conforme Acselrad (2005). O relato é sobre a dificuldade para dormir após a quadruplicação. Um dos comentários diz que o problema é o povo que se instala perto das empresas. Em resposta, uma pessoa conta que o balneário foi criado em 1948, a Vila Elza em 1953, a primeira empresa (Borregaard) se instalou em 1973, e diz "Eu nasci aqui e faço parte desta história. [...]. A empresa expandiu sem respeitar a população". Em resposta, há um comentário atribuindo à chegada da fábrica a intensificação das construções habitacionais, que seria uma responsabilidade da prefeitura. Outro comentário afirma que a empresa se situa entre os balneários Alvorada e Alegria e que os mesmos são próximos à zona central do município, de maneira que a fábrica não foi instalada em local distante da população.

Integrantes da ABA revelam que desde 2013 tentam vender suas residências com o objetivo de fugir do barulho ininterrupto em torno de 60 decibéis, do odor fétido que causa náuseas e dores de cabeça, das cinzas e material particulado que invade as residências e cobre as ruas, mas não há compradores. Outro aspecto destacado no documento da ABA é o medo 
permanente de conviver com o risco de acidentes por não saber como proceder, pois não houve treinamento para evacuação de área.

[...] [fevereiro de 2016] houve um estrondo que causou pânico aos moradores [...], pois a caldeira precisou ser despressurizada em caráter de emergência. As pessoas não sabiam o que fazer, pois não sabiam de onde vinha o estrondo, parecia um avião caindo sobre nossas casas, [...], o fato durou mais de uma hora e a empresa divulgou nota dizendo que foi por poucos minutos [...].

Nossas casas estão separadas da empresa por apenas uma rua, ficando caldeira, planta de cloro, digestor, picador [...], a menos de 100 metros dos nossos lares. [...].

Estamos sendo reféns da empresa, convivendo com o medo e com suas emissões, nunca foi apresentado um plano de evacuação ou realizado algum treinamento com moradores do local em caso de acidente em maior proporção não sabemos o que fazer e nem para onde correr.

[...].

Não podemos deixar de mencionar que existem três escolas no entorno da fábrica e um abrigo para menores, que ficam expostos a todas estas emissões e tem comprometido o seu desenvolvimento [...]. (ABA, 2017).

Em relação aos ruídos e barulho classificados pela vizinhança como absurdos e inaceitáveis, a Licença de Operação (LO) $n^{\text {o. }}$ 5144/2016, emitida pela Fundação Estadual Henrique Luis Roessler (Fepam), determina no item 5.5: "os níveis de ruído gerados pela atividade industrial deverão [...] considerando área mista, predominantemente residencial, devendo atender o limite máximo de ruído de $55 \mathrm{~dB}$ no período diurno e $50 \mathrm{~dB}$ no período noturno, [...]”. Entretanto, a vizinhança alega que este limite jamais foi respeitado, mostrando nas postagens que os decibéis costumam variar de 60 a 65 , durante o dia e/ou à noite.

De fato, a quadruplicação ampliou a produção da fábrica em mais de três vezes em relação à duplicação (anos 90), de 450.000 para 1.750 .000 toneladas por ano de celulose branqueada de eucalipto. A seguir, reproduzimos as informações da LO (Quadro 1) sobre a capacidade máxima produtiva anual e os respectivos produtos:

Quadro 1 - Produtos do megaempreendimento e capacidade máxima produtiva

\begin{tabular}{|c|c|c|}
\hline Quantidade & Unidade de medida (toneladas) & Descrição do produto \\
\hline 1.800 .000 & $\mathrm{tSA}$ & Celulose branqueada de eucalipto \\
\hline 33.600 & $\mathrm{t}$ & Cloro liquefeito \\
\hline 1.116 & $\mathrm{t}$ & Hidrogênio \\
\hline 72.000 & $\mathrm{t}$ & Papel de impressão e escrita \\
\hline 116.400 & $\mathrm{t}$ & Solução de Hidróxido de Sódio 33\% \\
\hline 24.000 & $\mathrm{t}$ & Solução de Hipoclorito de Sódio 12\% \\
\hline 42.000 & $\mathrm{t}$ & Solução de Ácido Clorídrico 33\% \\
\hline
\end{tabular}

Fonte: Fepam, LO n ${ }^{\circ} .5144 / 2016$.

Tamanho potencial produtivo mudou drasticamente a rotina da vizinhança. A postagem de 23 de junho de 2016 teve o maior número de comentários (até primeiro de julho). É um post com texto motivado por discussão ocorrida nos dias anteriores, traz duas imagens que reproduzem dois comentários, um pedido de reflexão sobre os impactos à saúde das pessoas e os casos de 
câncer assim como a falta de estatística [em Guaíba], e dois, o questionamento do que deveriam pensar sobre os laudos de água e ar divulgados pela própria empresa em seu site a respeito das emissões que faz. A vizinhança não acredita que o que sai das chaminés seja somente vapor de água conforme a discussão na rede social. $\mathrm{Na} \mathrm{LO}$, vimos em "Quanto à Preservação e à Conservação Ambiental", que no item 3.3, se confirma que algo mais é emitido: "deverá ser dada continuidade às atividades de biomonitoramento de dioxinas e furanos [grifo nosso] nas águas do lago Guaíba, junto à área de influência do ponto de lançamento dos efluentes líquidos tratados na indústria. [...].”. E, em se tratando de números portentosos de efluentes líquidos despejados em manancial que dessedenta a população de cinco municípios, temos um caso típico de interesse público a ser reportado pelo jornalismo. Pois, $93,4 \%$ da vazão máxima para o lançamento dos efluentes líquidos industriais e sanitários autorizada (de $165.356 \mathrm{~m}^{3} / \mathrm{dia}$ ), pertence à CMPC Celulose Riograndense (154.400 m³/dia). (BELMONTE, 2017).

Os dois posts mais compartilhados apresentam imagens das chaminés. Aquele datado de 19 de junho de 2016 teve 153 compartilhamentos e mostra uma foto noturna feita da areia da praia e ao fundo a megafumaça. Diz: "O problema é ambiental, mas o cenário é de zona de guerra". O debate nos comentários seguiu até 22 de junho. Recebeu 16 comentários criticando as emissões poluidoras. Mas houve manifestações como: de que a cidade ficaria sem empregos, de que se fosse tão ruim já teriam fechado a fábrica, de que todos usam papel, de que há hipócritas que se intoxicam com bebidas e cigarros, de que reclamam mas o esgoto cloacal vai para o lago Guaíba de onde se coleta a água para o abastecimento do município, que o objetivo é aumentar o valor para venda das casas próximas à empresa, de que as chaminés são monitoradas pela Fepam e de que se trata de vapor de água e não fumaça tóxica.

Já a publicação de 20 de julho de 2016 teve 89 compartilhamentos. Trouxe uma foto diurna com as chaminés emitindo nuvens gigantescas de fumaça. $O$ texto diz que a paisagem não perde em nada à Inglaterra industrial do século XVIII, ironizando a poluição decorrente da Revolução Industrial iniciada naquele país. Em um dos comentários, a pessoa relata que os carros estão sempre com partículas de algo branco e pergunta como estará o pulmão dela.

De volta à leitura da LO, vimos no item 5.1.1, que "o monitoramento da qualidade do ar, quanto aos parâmetros legislados (PTS - partículas totais em Suspensão, PI - Partículas Inaláveis, $\mathrm{SO}^{2}$ [Dióxido de Enxofre], $\mathrm{CO}$ [Monóxido de Carbono], $\mathrm{NO}^{2}$ [Dióxido de Nitrogênio], ERT (enxofre reduzido total) e ozônio, [...]" O que significa a confirmação da emissão de gases tóxicos à atmosfera ainda que haja monitoramento e supostos limites aceitáveis. Chamamos de "supostos limites aceitáveis" porque são fartos os testemunhos da vizinhança quanto aos sintomas provocados pelos referidos gases (e poderíamos considerar a fauna aqui também, seja doméstica ou não). Devemos ressaltar, que o item 5.6., que apresenta o "padrão de emissão a ser atendido" por caldeiras e fornos, especifica os limites de cada um e traz no subitem 5.6.6 que, "o somatório das emissões de Enxofre Reduzido Total (ETR) de todas as fontes de emissões da empresa não 
poderá ultrapassar a emissão máxima de $2,38 \mathrm{~kg} / \mathrm{h} ;[\ldots]$..”. Com isso, temos que a CMPC gaúcha está autorizada a emitir pelas chaminés até 2,38 quilos por hora de Enxofre Reduzido Total. A leitura da Licença de Operação do megaempreendimento permite compreender o porquê do fétido odor de ovo podre que, dependendo do vento, do sol (e outras variáveis descritas na LO) avança sobre os bairros próximos à fábrica mas pode atingir os mais distantes e, chegar à zona sul de Porto Alegre, como aliás já acontecia nos anos 1970 com a Borregaard.

A seguir transcrevemos trechos de comentários que evidenciam o temor da vizinhança principalmente em relação às emissões de gases e dúvidas sobre a possibilidade de proteção no uso de EPI's1, ao que o funcionário da empresa que costumava comentar as postagens, se manifesta não acreditando nessa necessidade por considerar que a vizinhança não se encontra em área de risco.

Comentário 1: [...] nós estamos a poucos metros desta área [de risco] e não temos proteção nenhuma, e o poder público, a empresa, a Fepam só vão correr atrás do prejuízo quando acontecer algum acidente como ocorreu em Mariana MG, [...], sai mais barato trabalhar durante anos arriscando a vida dos moradores e se acontecer o inesperado correr atrás do prejuízo do que trabalhar dentro dos padrões, orientar os moradores em caso de acidente, fazer o papel da boa vizinhança, é por isso que digo, eles só fazem o que é do interesse deles pra trazer lucro pra empresa, jamais irão se importar com a qualidade de vida dos moradores do entorno.

Comentário 2: Áreas de risco, exatamente, como o próprio nome diz, o risco é restrito a área, e quem atua nela tem ciência e treinamento para isso, bem como epi. Não tem necessidade nenhuma para distribuir epis para os vizinhos, pois como eu disse, por o $\mathrm{ClO} 2$ ser mais denso que o ar ele tende a ficar no mesmo local do possível vazamento. Quanto à ruído, isso é incontestável que vocês têm razão e temos de melhorar, estamos trabalhando para isso! (NÃOSOMOS, 2016).

A LO n ${ }^{0} \cdot 5144 / 2016$ é um documento rico em informações que deveria ser acessado por jornalistas e habitantes do município onde o megaempreendimento está instalado para facilitar a compreensão sobre a complexidade da atividade econômica de produção de celulose e papel, que recebe bilhões em investimento de recursos públicos. A prática do Jornalismo Ambiental nos impulsiona a aprofundar as pautas, a investigar e a ouvir muito além das boas notícias, como os lucros, a geração de receitas ou de empregos.

Desde a primeira fábrica instalada nos anos 1970, a Borregaard, a imprensa acompanhou proximamente os acontecimentos relacionados. Tanto que, os dois processos ${ }^{2}$ movidos na Justiça,

\footnotetext{
${ }^{2}$ Equipamentos de Proteção Individual.

${ }^{2} \mathrm{O}$ processo 595021817 foi movido em fevereiro de 1992 pela Agapan contra a Fepam e o Governo do Estado. O pedido era de garantia da retomada de uma audiência pública em Porto Alegre (de discussão do projeto de duplicação da fábrica de celulose em Guaíba) e anulação da licença emitida pelo órgão ambiental em 1989. Houve uma liminar em primeiro grau autorizando a retomada da audiência e suspendendo a duplicação da fábrica, mas a mesma acabou cassada pelo Tribunal de Justiça do RS. O processo 01192132320 é uma Ação Civil Pública de abril de 1992 movida
} 
contêm vários recortes de notícias dos jornais Zero Hora, Correio do Povo e Jornal do Comércio, dentre outros. As notícias traziam testemunhos das pessoas afetadas bem como informações sobre as emissões e os efluentes e os respectivos malefícios à saúde humana. A mobilização da Agapan junto aos meios de comunicação e dos professores e pesquisadores de universidades que eram filiados à entidade substanciou o trabalho dos jornalistas naquele período. Ao mesmo tempo, Lustosa e Benites (2008, p. 12) chamam a atenção para o volume de poluição gerada pela fábrica ainda antes da quadruplicação:

[...]. Quem assume a responsabilidade sobre os riscos que esse megainvestimento provocará? Qual o impacto sobre o aquecimento global desse "desenvolvimento sustentável"? O que dizem a respeito os meios empresariais e políticos, sempre tão parceiros e solidários? E a comunidade, os cidadãos, o que pensam disso?! (LUSTOSA; BENITES, 2008, p. 21).

Diante destes questionamentos, poderíamos supor que o jornalismo de referência, tendo em vista a relevância do tema, o traria ao debate público? Observando uma "tabela de valoresnotícia" desenhada por Silva (2014), no intuito de facilitar a operacionalização de análises de acontecimentos relatados no trabalho jornalístico, podemos afirmar que o conflito ambiental pode ser considerado como "notícia". A tabela reúne atributos de fatos noticiáveis, indicados por mais de uma dezena de autores reconhecidos desde Tobias Peucer à Mauro Wolff até o contemporâneo Nilson Lage. Na sequência, relacionamos os seguintes valores-notícia sobre as informações que obtivemos da pauta, a partir das postagens acima descritas, visando pensar sobre a sua validade para cobertura jornalística de todo e qualquer meio de comunicação: Impacto quanto ao número de pessoas afetadas por extrapolar os envolvidos no acidente conforme as denúncias feitas pelos moradores e moradoras do entorno da fábrica; Proeminência por envolver uma das maiores fábricas de produção de celulose do mundo; Conflito tanto pela disputa de sentidos em relação aos benefícios e os malefícios percebidos pelos habitantes do município de Guaíba evidenciados nas postagens da rede social, como pelas reivindicações da parcela guaibense que se sente atingida pelos impactos negativos da mega fábrica; Tragédia/Drama pelos aspectos do interesse humano, emoção e riscos à vida; Proximidade (geográfica e cultural) e Justiça devido às denúncias feitas pela vizinhança, tanto ao órgão estadual responsável pelo licenciamento como ao Ministério Público do Rio Grande do Sul.

Embora se perceba a presença destes valores-notícia acima arrolados no conflito ambiental (possuindo, portanto, potencial noticioso), nossa busca pela repercussão destes fatos na respectiva reparação referentes às denúncias constantes no inquérito civil n. 033/90 instaurado em 22/11/90 (com notícia de jornal e queixas dos moradores da Zona Sul de POA devido mau odor proveniente da fábrica); e uma Medida Liminar com medida suspensiva da operação da unidade de fabricação de cloro-soda e da ampliação da unidade de celulose. Lustosa e Benites (2008, p. 21) informam que o processo seguiu até 2001 quando foi assinado um termo de ajuste entre governo do Estado, Ministério Público e empresa "[...] que prevalece até hoje. Afinal, a fábrica de clorosoda já estava em funcionamento, a planta de celulose duplicada desde 1995”. 
mídia hegemônica resultou na quase invisibilidade deste debate. Com isso, nossa abordagem segue para um repensar do papel do jornalismo em relação aos temas da cidadania.

\subsection{Invisibilidade da cidadania na midiatização hegemônica}

A invisibilidade dos temas sociais da cidadania é recorrente quando o assunto é o tratamento dispensado pelos meios do jornalismo hegemônico. Para compreender a temática dos direitos e dos conflitos, aqui especialmente o direito à cidadania ambiental, é importante repensar de que forma se constitui a (in) visibilidade dos conflitos ambientais em relação ao que poderia ser entendido como compromisso essencial do jornalismo - a expressão da pluralidade, não restrita a fontes ouvidas, ou a fontes de financiamento, mas a pluralidade, aqui entendida a partir do conceito de "perspectivas". Assim, conforme Miguel e Biroli (2010, p. 72), é necessário que “[...] os diferentes grupos sociais tenham possibilidade de produzir informações a partir de suas próprias perspectivas, o que implica no descentramento do padrão de profissionalismo jornalístico e dos padrões de hierarquização da expressão [...]".

Para Soares (2009), a limitação do agendamento da crise social brasileira e da situação dos subalternizados (que geram as demandas sociais) é recorrente. Além disso, na sua avaliação, há apenas o tangenciamento das questões sociais, “[...] em especial nos eventos pontuais agudos (acidentes, calamidades, ocupações, confrontos), de modo que os direitos sociais, ligados à terceira geração da cidadania ${ }^{3}$, não formam um assunto privilegiado pela imprensa". (SOARES, 2008, p. 6).

Por outro lado, o processo de midiatização e visibilidade é ambivalente, pois a própria visibilidade pode corroborar com o processo de invisibilidade. Por exemplo, quando a aparição de certos grupos sociais é trazida como contra-modelos, ou seja, eles "são vistos" (mostrados) mas de forma negativa, perversa. Assim pode-se dizer que a midiatização da esfera pública "alimenta a ilusão de possibilidade de existência através do olhar do outro", por isso a autora aponta que seja importante pensar que a falta não é propriamente de visibilidade, mas de escuta. (VAZ, 2011, p. 197).

A esfera pública é, pois, por excelência, o lugar do encontro com o outro. E é sobre essa esfera e sua força centrípeta, geradora de sociabilidade, que nos interessa falar; essa esfera para a qual os indivíduos olham e se sentem instados a produzir opiniões, agir, trabalhar, criar, comportar-se, sempre par rapport a outrem (SALES, 2007, p. 97 apud VAZ, 2011, p. 195).

A falta de escuta ou empatia em relação aos direitos pode ser entendida desde a captura

\footnotetext{
${ }^{3}$ Conforme Sachs (1998, p.156), a inclusão do direito ao ambiente emerge como um dos direitos de terceira geração. In: SACHS, Ignacy. Desenvolvimento, direitos humanos e cidadania. Direitos humanos no século XXI, 1998.
} 
da esfera pública pelo jornalismo hegemônico, no qual não se encontra a visibilidade a certas populações ou aos seus problemas/conflitos, pois esbarram na ideologia dominante. As práticas jornalísticas são arraigadas na sua estrutura de negócio, antes que na sua função educativa ou de serviço público. Contudo, o jornalismo, quando considerado um serviço público à população, deve estar atento e contribuir subsidiando os debates com as informações a respeito das disputas inerentes da construção da cidadania numa sociedade democrática. Em relação às narrativas, pode-se acrescentar ainda a ideia de um jornalismo compassivo, considerado como uma abordagem que busca favorecer "o cultivo do florescimento humano, tanto individual quanto coletivamente." (LAMAS; SCHWAAB, 2017, p. 35). Ao privilegiar as relações sociais, a narrativa pode dar melhores condições de contribuições ao debate público.

Em contrapartida, com a proliferação das redes digitais, também é possível visualizar movimentos contra-hegemônicos, que buscam a instaurar um espaço de fala, de visibilidade e de perspectivas. Para discutir o tema à margem da grande imprensa, movimentos organizados lançam mão da comunicação direta, exercendo ao mesmo tempo o potencial da internet para a visibilidade, a representação política, fazendo ainda a crítica midiática. Bucci (2000, p. 47) considera que "[...] o cidadão tem preparo suficiente para tomar partido em relação a dilemas éticos e também técnicos do jornalismo".

Na questão ambiental e na crítica feita pelo jornalismo ambiental, acredita-se que é necessário “[...] incorporar a participação, elemento central do nosso tempo, em que os cidadãos têm a possibilidade de serem incluídos mais fortemente na discussão da vida social, trazendo luzes para as preocupações ambientais [...]" (GIRARDI et al, 2012, p. 149). Os estudos sobre jornalismo ambiental também destacam a realidade da cobertura sobre meio ambiente, em diferentes situações, nas quais são recorrentes as conclusões acerca da predominância das fontes oficiais e da invisibilidade da dimensão ambiental e dos movimentos em prol da qualidade de vida. O jornalismo necessita de uma transformação em direção à escuta das populações, da comunidade, de seus direitos e necessidades.

O apelo à cidadania expressa-se hoje por essa contínua entrada em cena de novos atores que procuram constituir-se como autoridades para falar de si mesmos. Cidadania, além de ser sentimento de pertencimento a uma nação, a uma comunidade, a um projeto da sociedade moderna, vai sendo também relacionada à capacidade desses atores articularem demandas e apresentarem soluções (SOARES, 2009, p.135).

De fato, atender aos anseios da cidadania é uma ação convergente com as premissas do jornalismo, que vai além de escolhas concernentes à linha editorial das empresas de comunicação.

\section{Metodologia}

Inicialmente, a busca pelas notícias a serem analisadas se deu nos sites dos dois principais 
jornais estaduais, o Correio do Povo e o Zero Hora. O resultado foi apenas uma notícia do CP e nenhuma de $\mathrm{ZH}$ relacionando o sofrimento da vizinhança da fábrica ao impacto do megaempreendimento, no período compreendido entre maio de 2016 e maio de 2017, ou seja, o segundo ano após a inauguração da quadruplicação da fábrica. Porém, uma notícia ${ }^{4}$ foi encontrada em ZH em 2016 com o viés econômico, como o título e a linha de apoio, respectivamente, definem: "Movimentação de celulose aumenta $1000 \%$ no Porto de Rio Grande" e "Produção é feita pela empresa Celulose Riograndense e tem como destino Europa e Ásia". Não obstante tenha sido este o resultado na busca no site de $\mathrm{ZH}$, destacamos que outros meios de comunicação do Grupo RBS ${ }^{5}$ pautaram a situação da vizinhança da fábrica quadruplicada. Para os anos seguintes à quadruplicação $(2017,2018,2019)$ a busca nos dois sites dos dois maiores jornais do Estado não indicou nenhuma notícia com a pauta da situação da vizinhança. Não que os impactos tenham cessado no Balneário Alegria, em Guaíba.

Para analisar a relação entre as questões da cidadania, que envolvem o caso da convivência entre a fábrica da CMPC Celulose Riograndense e a vizinhança, lançamos mão da Análise de Conteúdo (AC). É um método que pode ser aplicado tanto na pesquisa quantitativa como na investigação qualitativa, sendo que, na primeira, o que serve de informação é a frequência com que surgem certas características do conteúdo, enquanto na segunda é a presença ou a ausência de uma dada característica de conteúdo ou de um conjunto de características num determinado fragmento de mensagem que é levado em consideração (BARDIN, 1994). A pesquisa aqui relatada tem viés qualitativo, está voltada à questão sobre as características da mensagem, ou seja, "seu valor informacional, as palavras, argumentos e ideias nela expressos. É o que constitui uma análise temática." (MORAES, 1999, s/p). Seguimos as proposições de Moraes (1999): preparação das informações, unitarização do conteúdo, categorização e interpretação. Após a verificação da diminuta cobertura nos jornais $\mathrm{CP}$ e $\mathrm{ZH}$, em relação às notícias sobre o conflito ambiental em questão, identificamos o importante papel difusor exercido pela página de rede social "Não-Somos".

Desta forma, acompanhar a visibilidade que a página de rede social "Não Somos" deu ao sofrimento da vizinhança da fábrica da CMPC Celulose Riograndense nos possibilitou encontrar notícias publicadas por outros meios de comunicação sobre o tema desprezado pelos dois diários de referência. Em seis posts, vimos o compartilhamento além da já referida notícia do CP, de duas do jornal Extra Classe; duas do site da Agapan e uma no site da AMA de Guaíba.

\footnotetext{
${ }^{4}$ Disponível em: https://gauchazh.clicrbs.com.br/geral/noticia/2016/04/movimentacao-de-celulose-aumenta-1000-noporto-de-rio-grande-cj5wan47n1iwnxbj0rivs64dm.html Acesso em: jul. 2019.

${ }^{5}$ O Grupo RBS, fundado em 1957 em Porto Alegre, possui diversos negócios na comunicação: 12 emissoras de TV aberta afiliadas à Rede Globo, 16 emissoras de rádio e 3 jornais, sendo além do Zero Hora, o Diário Gaúcho e o Pioneiro. Possui também empresa da área de tecnologia através da qual atua nas áreas de mídia digital e tecnologia, mobile e e-commerce segmentado. Possui ainda empresa de eventos, uma editora, uma gráfica, etc.
} 
A seguir, descrevemos o conteúdo das referidas notícias compartilhadas pela página "Não-Somos", as quais foram analisadas por seu valor informacional, tendo em vista as categorias da pluralidade de perspectivas e as dimensões do conflito ambiental.

\section{Visibilidade das perspectivas e dimensões do conflito}

O grupo "Não-Somos" posta a matéria do Correio do Povo6, "Celulose Riograndense será autuada por vazamento no Guaíba”, publicada em 17 de dezembro de 2016. A notícia tem uma abordagem eminentemente técnica em relação ao conflito ambiental. Desta forma, não há como identificar a resistência dos moradores; apenas se refere aos aspectos detectados por técnicos da Fepam e um evento específico (CELULOSE [...], 2016). O vazamento de licor (lixívia) que chegou no leito do Lago Guaíba em volume avaliado em cem metros cúbicos. Tratase de uma notícia típica de "acidente ambiental" o qual é tratado como algo não frequente e as razões (causas) ficam para serem apuradas.

A questão do controle é trazida no post que compartilha, em 25 de junho de 2016, o link da reportagem do jornal Extra Classe 7 "Quem fiscaliza a fábrica”. O jornal é ligado ao Sindicato dos Professores e costuma abordar os temas de forma crítica. Neste texto, questiona-se principalmente o grau de segurança do empreendimento. Relata os passos de licenciamento e autorizações feitas à companhia além dos recentes vazamentos e paralisações por causa de segurança. Um ponto importante à causa dos moradores é a exigência legal de um plano em relação aos riscos, que deve prever o mapeamento, a redução e a orientação às populações afetadas (SANDRI, 2016).

Também no dia 25 de junho de 2016 outra postagem traz comentário direcionado à imprensa hegemônica, classificando-a de subvencionada pelo marketing da fábrica, o que dificulta um possível debate. A reportagem compartilhada foi publicada no Extra Classe com o título “Até quando esperar?". O texto apresenta em primeiro lugar a fonte popular, com a fala da moradora questionando a falta de informações diante dos vários casos de acidentes e vazamentos e questiona a postura da Fepam em não se posicionar sobre o último caso de vazamento de dióxido de cloro, datado de 5 de maio. Os acidentes atingiram vários trabalhadores e foi motivo de ações judiciais contra a empresa, que fez um acordo com o Ministério Público.

No dia 15 de junho de 2016 foi compartilhada a reportagem do site da Agapan "Moradores criam associação para se defenderem dos impactos de fábrica de celulose". Esta é a

\footnotetext{
${ }^{6}$ Fundado em 1895, atualmente é dirigido pelo Grupo Record, ligado à Igreja Universal do Reino de Deus. Conforme o divulgado, a tiragem é de 102.335 exemplares impressos, que circulam em todos os municípios do RS, e em parte dos municípios de SC e PR.

${ }^{7}$ Fundado em 1996 é uma publicação do Sindicato dos Professores do Rio Grande do Sul (Sinpro/RS). Informa que a periodicidade é mensal e a tiragem é de 25 mil exemplares.
} 
notícia da criação da Associação Comunitária do Balneário Alegria (ABA), que deve atuar na defesa da habitação dos moradores da região, auxiliando num projeto sustentável. A notícia é acompanhada por entrevista com a presidente da ABA, Cristiane Montemezzo Simões. O destaque são os problemas enfrentados pela população, como barulho e emissão de cinzas (LACERDA, 2016a).

O site da Agapan ${ }^{8}$ publicou em 19 de junho de 2016, a matéria "Escritor de A Fraude da Celulose visita Guaíba". A notícia sobre a visita do jornalista Victor Bacchetta, autor cujo título do livro foi referido na matéria, destacou o roteiro do jornalista conhecendo o entorno do empreendimento, e o diálogo com moradores e ambientalistas, trazendo críticas ao modelo de desenvolvimento e a falta de alternativas (LACERDA, 2016b).

Em 23 de junho de 2016, há o compartilhamento da matéria "Jornalista uruguaio visita Guaíba, critica indústria da celulose e incentiva mobilização popular", publicada pelo site da AMA $^{9}$. A ênfase da reportagem foi o debate entre integrantes do movimento de Guaíba e o jornalista Victor Bacchetta especialmente em relação à importância da organização e da mobilização popular para buscar soluções contra a degradação ambiental e uma vida de qualidade (AMIGOS DO MEIO AMBIENTE, 2016). Ao fazer esta divulgação fica explícita a disposição dos moradores em lutar e em buscar parcerias para o enfrentamento do conflito ambiental. Esta comunicação pode ser entendida como uma forma de articulação e fortalecimento do movimento.

A partir do entendimento da relevância do jornalismo para a construção da cidadania, elaboramos duas categorias para análise das notícias: a) escuta à cidadania: fontes citadas; b) temáticas relacionadas às dimensões do conflito ambiental, por demandas dos moradores (poluição, barulho, cheiro); da empresa (investimentos, lucros, licenciamento) e do governo (fiscalização, licenciamento, empregos).

A organização das informações resultantes da nossa análise, possibilita a apresentação de duas ilustrações. Em primeiro lugar, podemos verificar (Figura 2) que a escuta de fontes, considerada uma forma de humanização do jornalismo e de trabalho da pluralidade de perspectivas, conforme discutimos anteriormente, fica aqui comprometida na matéria do Correio do Povo (que ouve apenas técnicos e governo); bem como do site de AMA (que traz moradores e ambientalistas). No entanto, do ponto de vista do alcance das duas publicações, é notório que o jornal Correio do Povo tem mais leitores e repercussão, desta forma, deveria também buscar dar espaço às perspectivas da cidadania como um todo. As notícias da Agapan ouviram moradores, ambientalistas e governo dando, portanto, maior sentido à controvérsia, expondo com pluralidade o conflito. Verificamos ainda que o jornal Extra Classe trouxe quatro perspectivas diferentes,

\footnotetext{
${ }^{8}$ Associação Gaúcha de Proteção ao Ambiente Natural, entidade ambientalista fundada em 1971 e sediada em Porto Alegre (RS).

${ }^{9}$ Amigos do Meio Ambiente, entidade ambientalista fundada em 1990 em Guaíba (RS).
} 
tanto de ambientalistas, moradores, quanto do governo e da empresa, sendo uma abordagem bastante completa do ponto de vista da construção da cidadania.

Figura 2 - Fontes citadas/ouvidas nas notícias.

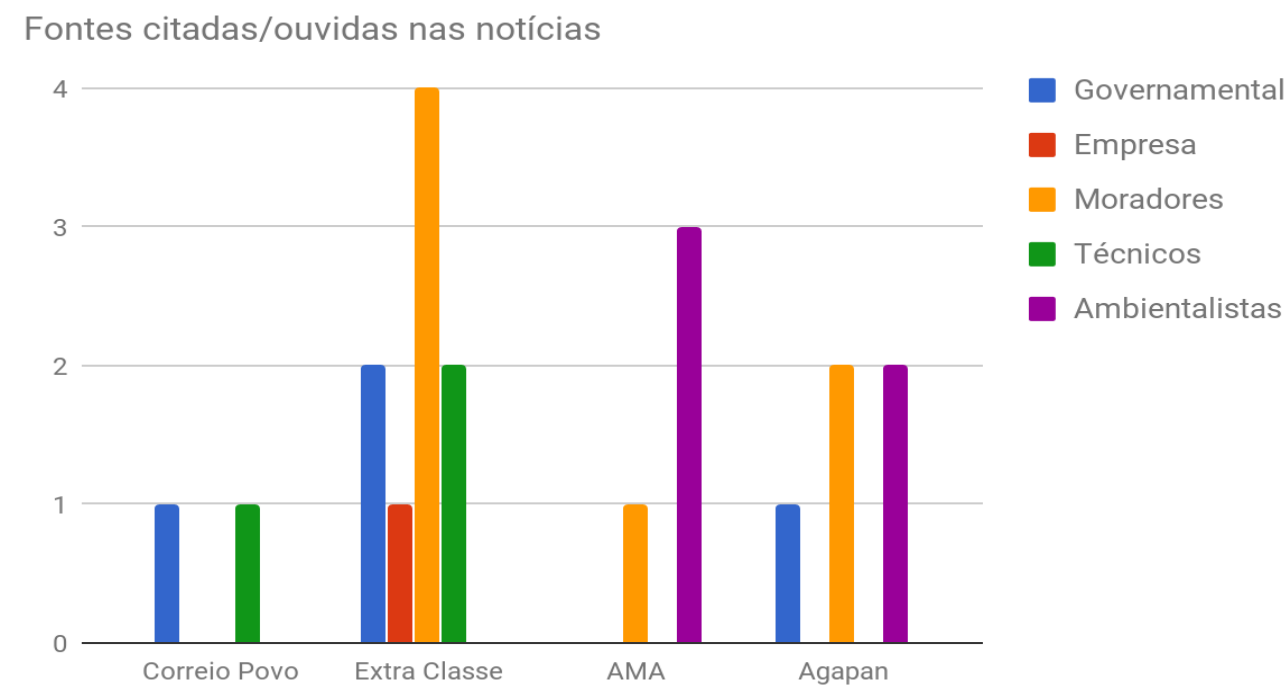

Fonte: Elaboração própria.

Em segundo lugar, para compreender de que forma as notícias deram espaço às demandas do conflito ambiental, tomamos as quatro dimensões definidas por Acselrad (2005) em torno da quadruplicação da fábrica, e as dispomos a seguir (Quadro 2):

Quadro 2 - Demandas do conflito ambiental

\begin{tabular}{|c|c|c|c|c|}
\hline $\begin{array}{c}\text { Meio de } \\
\text { comunicação }\end{array}$ & Fábrica & Moradores & Governo & Dimensão \\
\hline Correio do Povo & - & - & $\begin{array}{c}\text { Avaliação do } \\
\text { vazamento de } \\
\text { licor e verificação } \\
\text { da água } \\
\text { Medidas } \\
\text { preventivas a ser } \\
\text { exigidas }\end{array}$ & $\begin{array}{l}\text { Apropriação } \\
\text { material } \\
\text { Apropriação } \\
\text { simbólica }\end{array}$ \\
\hline Extra Classe & $\begin{array}{l}\text { Resultados } \\
\text { positivos; } \\
\text { expansão e } \\
\text { produtividade; } \\
\text { garantia de } \\
\text { matéria-prima; } \\
\text { promessa de } \\
\text { autorização; } \\
\text { redução de } \\
\text { consumo. }\end{array}$ & $\begin{array}{l}\text { Afrouxamento da } \\
\text { legislação; } \\
\text { Falta de } \\
\text { informação e } \\
\text { alertas; nível de } \\
\text { ruído e mau } \\
\text { cheiro } \\
\text { Poluentes e } \\
\text { resíduos; } \\
\text { vazamento e } \\
\text { trabalhadores; } \\
\text { coluna de fumaça }\end{array}$ & $\begin{array}{l}\text { Fiscalização de } \\
\text { irregularidades; } \\
\text { Plano de } \\
\text { emergência; não } \\
\text { risco à } \\
\text { comunidade; } \\
\text { empresa têm } \\
\text { estudos; incêndios } \\
\text { de baixo risco }\end{array}$ & $\begin{array}{l}\text { Apropriação } \\
\text { material } \\
\text { Apropriação } \\
\text { simbólica } \\
\text { Durabilidade } \\
\text { Interatividade }\end{array}$ \\
\hline Agapan & - & $\begin{array}{l}\text { Defesa do meio } \\
\text { ambiente; }\end{array}$ & - & $\begin{array}{l}\text { Apropriação } \\
\text { material }\end{array}$ \\
\hline
\end{tabular}




\begin{tabular}{|c|c|c|c|c|}
\hline & & $\begin{array}{l}\text { Despejo de } \\
\text { resíduos no Lago; } \\
\text { Medo de } \\
\text { acidentes; } \\
\text { Cinzas nas casas; } \\
\text { fechamento de } \\
\text { locais de lazer e } \\
\text { clima de } \\
\text { abandono; } \\
\text { Forte odor; } \\
\text { barulho além do } \\
\text { limite; morte do } \\
\text { manancial. }\end{array}$ & & $\begin{array}{l}\text { Durabilidade } \\
\text { Interatividade }\end{array}$ \\
\hline AMA & - & $\begin{array}{l}\text { Partículas e } \\
\text { espuma sobre as } \\
\text { residências; } \\
\text { trepidação de } \\
\text { móveis e janelas } \\
\text { Ruído } \\
\text { permanente; odor } \\
\text { forte e incômodo; } \\
\text { densa fumaça; } \\
\text { positiva a criação } \\
\text { da associação }\end{array}$ & - & $\begin{array}{l}\text { Durabilidade } \\
\text { Interatividade }\end{array}$ \\
\hline
\end{tabular}

Fonte: Elaboração própria.

Ao observar o Quadro 2, podemos salientar que o jornal Correio do Povo, ao apresentar as dimensões da apropriação material e apropriação simbólica, apenas reforça o discurso do progresso a qualquer preço, pois não inclui as demais dimensões que podem colocar em xeque o uso do Lago pela fábrica, assim como a ideia de desenvolvimento. Esconde-se, por meio de um texto mais técnico e do gênero informativo, dimensões constitutivas do conflito ambiental. Em relação às notícias do Extra Classe, vimos todas as dimensões do conflito, inclusive as dimensões de durabilidade e interatividade, pois a causa dos moradores se coloca a partir das consequências das apropriações materiais e simbólicas realizadas pela fábrica. O site da Agapan não trabalhou a apropriação simbólica que se traduz, neste caso, ao discurso dominante de "sustentabilidade do negócio" da empresa. Ou seja, opta especificamente por não valorizar este tema e sim as demais dimensões, especialmente as de durabilidade e interatividade, as quais constituem as ameaças ao uso social do território e a poluição já evidenciada pelos moradores. Por fim, vimos que o site da AMA também se limitou às demandas dos moradores, que sofrem diretamente o resultado da implantação da fábrica próximo às suas casas. 


\section{Considerações finais}

O percurso deste trabalho nos permite concluir que o jornalismo de referência trouxe parca visibilidade ao conflito ambiental em torno da quadruplicação da fábrica de celulose no Rio Grande do Sul. Percebemos que a ideia de trazer pluralidade no sentido das perspectivas (MIGUEL; BIROLI, 2010) não se efetivou no Correio do Povo, além do que outro jornal de referência no RS, o Zero Hora, silenciou sobre o tema. Com a análise das fontes citadas, concluímos que a escuta dos moradores e suas demandas obteve visibilidade no Facebook, na página "Não-Somos", que compartilhou inúmeras informações que poderiam ter sido investigadas e aprofundadas pelo jornalismo, além desta página ter difundido as notícias de um meio sindical e duas entidades ambientais, respectivamente: Extra Classe, Agapan e AMA.

O engajamento ao tema dos direitos e da cidadania, portanto, encontra-se muito frágil no jornalismo e percebemos isso na avaliação das demandas das dimensões do conflito ambiental (ACSELRAD, 2005). Constatamos que pôr em questão a apropriação material e a apropriação simbólica dos bens naturais e coletivos foi um trabalho realizado fora do âmbito do jornalismo de referência. Com esta análise, concluímos que urge ao jornalismo a incorporação das perspectivas dissonantes na cobertura de conflitos ambientais, invocando, como indica Girardi et al. (2012), a participação como o foco das notícias.

\section{REFERÊNCIAS}

ACSELRAD, Henri. As práticas espaciais e o campo dos conflitos ambientais. In: Acselrad, Henri (org.). Conflitos ambientais no Brasil. Rio de Janeiro: Relume Dumará, 2005. p.13-35.

AMIGOS DO MEIO AMBIENTE. Jornalista uruguaio visita Guaíba, critica indústria da celulose e incentiva mobilização popular. Guaíba: AMA, 2016. Disponível em: http://amaguaiba.org/2016/06/20/jornalista-uruguaio-visita-guaiba-critica-industria-da-celulosee-incentiva-mobilizacao-popular/. Acesso em: set. 2019.

ASSOCIAÇÃO DOS MORADORES DO BALNEÁRIO ALEGRIA. Documento. Guaíba: ABA, 25 maio 2017. 2f.

BARENHO, Cíntia Pereira. A Função da União Europeia no desempoderamento das mulheres no Sul através da conversão dos ecossistemas locais em plantações de árvores: estudo de caso Pampa gaúcho. Porto Alegre: Amigos da Terra Brasil, 2008.

BELMONTE, Roberto Villar. Indústrias. Porto Alegre: GuaíbaDados, 2017. Disponível em: https://www.ufrgs.br/jordi/guaibadados/2017/02/15/industrias/. Acesso em: set. 2019.

BINKOWSKI, Patrícia. Conflitos ambientais e significados sociais em torno da expansão da silvicultura de eucalipto na "Metade Sul” do Rio Grande do Sul. 2009. 212f. Dissertação (Mestrado em Desenvolvimento Rural) - Faculdade de Ciências Econômicas, Universidade Federal do Rio Grande do Sul, Porto Alegre, 2009. 
CALDAS, Cadu. Celulose Riograndense acionará as máquinas da nova unidade. Jornal Zero Hora, Porto Alegre, 1 maio 2015. Disponível em:

http://zh.clicrbs.com.br/rs/noticia/2015/05/celulose-riograndense-acionara-as-maquinas-danova-unidade-4751506.html. Acesso em: set. 2019.

CELULOSE Riograndense será autuada por vazamento no Guaíba. Correio do Povo, Porto Alegre, 2016. Disponível em:

https://www.correiodopovo.com.br/not\%C3\%ADcias/geral/celulose-riograndense-

ser\%C3\%A1-autuada-por-vazamento-no-gua\%C3\%ADba-1.219589. Acesso em: set. 2019.

GIRARDI, Ilza Maria Tourinho et al. Caminhos e descaminhos do Jornalismo Ambiental.

Revista Comunicação \& Sociedade, São Bernardo do Campo, v. 34, n. 1, p. 131-152. jul./dez. 2012.

INSTITUTO BRASILEIRO DE GEOGRAFIA E ESTATÍSTICA. IBGE Cidades. Rio de Janeiro: IBGE, 2019.

LACERDA, Heverton. Escritor de A Fraude da Celulose visita Guaíba. Porto Alegre: AGAPAN, 2016b. Disponível em: http://www.agapan.org.br/2016/06/escritor-de-fraude-dacelulose-visita.html?m=1. Acesso em: set. 2019.

LACERDA, Heverton. Moradores criam associação para se defenderem dos impactos de fábrica de celulose. Porto Alegre: AGAPAN, 2016a. Disponível em: http://www.agapan.org.br/2016/06/guaiba-moradores-criam-associacao-para.html. Acesso em: set. 2019.

LAMAS, João Pedro; SCHWAAB, Reges. Jornalismo compassivo: aproximações preliminares a um conceito em construção. Revista Pauta Geral-Estudos em Jornalismo, Ponta Grossa, v. 4, n. 2, p. 21-37, jul./dez. 2017.

MIGUEL, Luis Felipe; BIROLI, Flávia. A produção da imparcialidade: a construção do discurso universal a partir da perspectiva jornalística. Revista Brasileira de Ciências Sociais, São Paulo, v. 25, n. 73. p. 59-76, 2010.

MORAES, Roque. Análise de conteúdo. Revista Educação, Porto Alegre, v. 22, n. 37, p. 7-32, 1999.

NENÊ, Ulisses. Vizinhos da Celulose Riograndense sofrem com mau cheiro, barulho e o medo de algo pior. Porto Alegre: EcoAgência, 2017. Disponível em: http://www.ecoagencia.com.br/?open=noticias\&id=VZISXRVVONIYHpkcOZlVaNGbKVVVB 1TP. Acesso em: set. 2019.

SANDRI, Sinara. Quem fiscaliza a fábrica. Extra Classe, Porto Alegre, 2016. Disponível em: http://www.extraclasse.org.br/edicoes/2016/03/quem-fiscaliza-a-fabrica/. Acesso em: set. 2019.

SILVA, Gislene. Para pensar critérios de noticiabilidade. In: Critérios de noticiabilidade problemas conceituais e aplicações. SILVA, Gislene; SILVA, Marcos Paulo da; FERNANDES, Mario Luiz (org.). Florianópolis: Insular, 2014. p. 51-69.

SOARES, Murilo César. Jornalismo e Cidadania em duas abordagens. In: ENCONTRO DA COMPÓS, 17. 2008, São Paulo. Anais [...]. Belo Horizonte: Compós, 2008. p. 1-14. Disponível em: http://www.compos.org.br/data/biblioteca_373.pdf. Acesso em: set. 2019.

SOARES, Murilo César. Representações, jornalismo e a esfera pública democrática. São Paulo: Cultura Acadêmica, 2009. 
WIKIMAPIA. Mapas. 2017. Disponível em: http://wikimapia.org/\#lang=pt\&lat=30.136628\&lon=-51.329112\&z=15\&m=b\&v=1. Acesso em: set. 2019.

Artigo recebido em: 2019-05-30

Artigo reapresentado em: 2019-08-14

Artigo aceito para publicação em: 2019-10-07 